\title{
Technical assistance to the Institute of Reproductive Health, Georgetown University in researching introduction strategies for the Standard Days contraceptive method (SDM)
}

\author{
Saumya RamaRao \\ Population Council \\ James R. Foreit \\ Population Council
}

Follow this and additional works at: https://knowledgecommons.popcouncil.org/departments_sbsr-rh

Part of the Demography, Population, and Ecology Commons, Health Services Research Commons, International Public Health Commons, Public Health Education and Promotion Commons, and the Women's Health Commons

How does access to this work benefit you? Let us know!

\section{Recommended Citation}

RamaRao, Saumya and James R. Foreit. 2007. "Technical assistance to the Institute of Reproductive Health, Georgetown University in researching introduction strategies for the Standard Days contraceptive method (SDM)," FRONTIERS Final Report. Washington, DC: Population Council. 
TECHNICAL ASSISTANCE TO THE INSTITUTE

OF REPRODUCTIVE HEALTH, GEORGETOWN UNIVERSITY

IN RESEARCHING INTRODUCTION STRATEGIES FOR THE STANDARD DAYS CONTRACEPTIVE METHOD (SDM)

\author{
Saumya Ramaro
}

James R. Foreit

The Population Council

July 2007

This study was funded by the U.S. AGENCY FOR INTERNATIONAL DEVELOPMENT (USAID) under the terms of Cooperative Agreement Number HRN-A-00-98-00012-00 and Subproject number 5800

53081. The opinions expressed herein are those of the authors and do not necessarily reflect the views of USAI
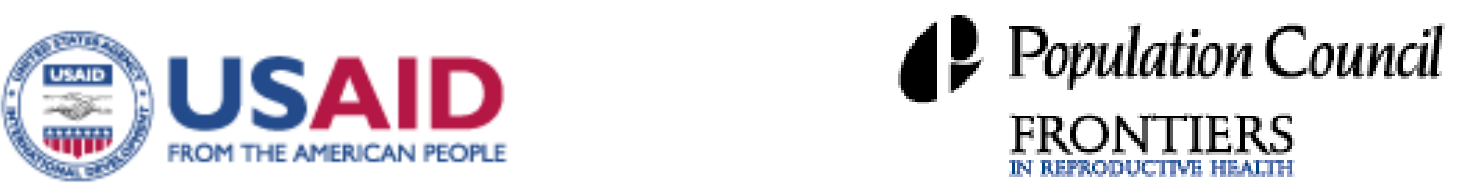


\section{Introduction}

The Institute of Reproductive Health (IRH), Georgetown University tested the impact of introducing the Standard Days method (SDM) with the technical assistance (TA) of Population Council Staff members Dr. Saumya Ramarao and Dr. James Foreit. Dr. Ramarao provided TA between June 2004 and May 2006 in introduction strategies and economic evaluation of SDM pilot and scale-up activities in Jharkand, India. Dr. Foreit provided TA between March 2004 and October 2005 in the design and analysis of an evaluation of the effectiveness of a mass media campaign for introducing the SDM in Ecuador.

\section{India Technical Assistance}

The technical assistance objectives were:

- Provide IRH with technical assistance for field level implementation of SDM introduction and scaling-up in Jharkand, India

- Provide IRH with technical assistance for the conduct of economic analyses in Jharkand, India and for replication in other study sites

Products expected at the end of this stage of the project were the following:

- Description of status of implementation upon completion of technical assistance

- A report of the Jharkand economic analysis

- An accompanying Power Point presentation and policy brief for dissemination to policy makers and program managers

Activities performed. The primary responsibility of FRONTIERS was designing the cost study and guiding IRH and local partners in collecting and analyzing the data. This approach was chosen by FRONTIERS to maximize technology and skills transfer to IRH and local partners so that they would be able to conduct such analyses independently in the future.

With this approach in mind, the following activities were conducted:

- A half day workshop on the methodology of the cost analysis for the three country principal investigators

- TA for the development of data collection forms

- Design of a template for data entry and analysis

- TA in the use of the template, analysis, and interpretation of findings.

Status. As of April 2007, IRH is in the process of writing the final report including a section on the cost analyses carried out. The TA provided was successful in transferring 
cost analysis technology. IRH was able to independently collect cost information, analyze the data and write a final report.

\section{Ecuador Technical Assistance}

The technical assistance objectives were:

- To assist in the design and analysis of data collection instruments for evaluating the results of a television advertising campaign to increase distribution of the SDM. The effects of the campaign were to be measured on SDM commercial pharmacy sales and distribution through CEMOPLAF and Ministry of Health (MOH) Clinics.

- To familiarize IRH and CEMOPLAF staff with mass media evaluation techniques

\section{Products expected:}

- Assistance in designing pre- and post- campaign questionnaires to measure changes in SDM knowledge, attitudes, and use

- Creation of a form to record calls about the SDM to the CEMOPLAF hotline

- Design of mystery shopper checklists to evaluate information given by the pharmacist to prospective SDM users, CEMOPLAF, and the MOH

- Assistance in analysis and interpretation of data obtained from the above instruments

Activities performed. Instrument design was accomplished during a visit to CEMOPLAF in Quito, Ecuador. Upon completion of the TV advertising campaign and a three-month post campaign period (to permit analysis of longer term campaign effects), a second visit was made to assist in the analysis of the campaign data, and to help with an end of project seminar. The evaluation showed that pharmacies are not an effective strategy for distributing the SDM. Few pharmacies agreed to sell the method and only a handful of clients purchased the product. The major impact of the TV campaign was to increase knowledge of the SDM, but attitudes towards the safety and effectiveness of natural methods remained unchanged. CEMOPLAF clinic staff provided significantly better counseling in use and greater distribution of the method than either pharmacies or $\mathrm{MOH}$ clinics.

Status. IRH continues to work with CEMOPLAF in researching natural methods. IRH staff made a presentation on the results of the TV campaign at the 2006 APHA meeting. IRH staff working with CEMOPLAF now undertake all instrument design without FRONTIERS assistance. 


\section{Conclusion}

FRONTIERS technical assistance had the immediate effect of allowing IRH to carry out evaluations of the SDM in Asia and Latin America. The IRH studies also produced important lessons learned on strategies for the introduction of natural methods. IRH staff responsible for the India and Ecuador projects learned specific skills in cost-analysis and research instrument design. 